\title{
THE ANAESTHETIC MANAGEMENT OF PELVIC LAPAROSCOPY
}

\author{
R.K. CALVERLEY, M.D., F.R.C.P.(C) AND L.C. JeNKINS, B.A., M.D., C.M., F.R.C.P.(c)
}

Pelvic laparoscopy or peritoneoscopy may be defined as the endoscopic examination of the pelvic organs through the anterior abdominal wall. Recent improvements in instrumentation and technique have increased the popularity of this procedure. ${ }^{1,2}$

In some situations laparoscopy has several advantages over pelvic laparotomy and culdoscopy. Laparotomy is more traumatic and is not as well accepted by patients. The higher morbidity of laparotomy requires a more protracted hospitalization. After laparoscopy the patient is frequently ready to return home on the following day.

When contrasted with culdoscopy, laparoscopy offers better visualization of the pelvic viscera.

\section{Surgical Technique}

After the induction of general anaesthesia, the patient is positioned in the lithotomy position with the arms by the side to improve the surgeon's access. A small midline incision is made immediately caudal to the umbilicus and a Verres needle is introduced into the peritoneal cavity. Three to five liters of carbon dioxide are insufflated and the patient is placed in a moderate head-down tilt of about 20 degrees. The surgeon inserts a trocar and attaches an external light source to the laparoscope. While the examination proceeds, additional smaller volumes of carbon dioxide may be required to compensate for leakage of carbon dioxide through the incision.

After the examination is completed, the patient is placed supine and the residual carbon dioxide is vented through the trocar.

An experienced laparoscopist may require only 15 minutes for the procedure unless subsequent surgery is performed. Anaesthetic time is usually at least 45 minutes.

\section{INDICATIONS FOR LAPAROSCOPY}

The indications for laparoscopy include diagnostic, therapeutic, research and non-gynaecological indications (Table I).

Presented at the 1972 Western Division Meeting of the Canadian Anaesthetists' Society. From Departments of Anaesthesia, University of British Columbia and Vancouver General Hospital. 
TABLE I

INDICATIONS FOR LAPAROSCOPY

\begin{tabular}{lc}
\hline Diagnostic & Research \\
Pelvic Pain & Photography \\
Infertility & Collection of ova and spermatozoa \\
Pelvic Mass & Collection of fluid from cysts \\
Endometriosis & Assessment of the ovarian response to \\
Congenital anomalies & hormonal stimulation \\
Therapeutic & Non-Gynaecological \\
Sterilization & Liver biopsy \\
Diathermy for endometriosis & Examination of the appendix and bowel \\
Incision of ovary in Stein Leventhal & Examination for metastases \\
Division of adhesions & \\
\hline
\end{tabular}

\section{Vancouver General Hospital Experience}

The successful introduction of laparoscopy as a routine gynaecological procedure resulted from teamwork and co-operation between the surgeon and anaesthetist. Laparoscopy has been performed at the Vancouver General Hospital since January, 1970. As gynaecologists gained experience, more laparoscopies have been performed; 74 laparoscopies in 1970 and 150 in 1971. At the present time an average of 20 elective and 4 emergency laparoscopies are carried out each month.

We have learned that the successful anaesthetic management of a laparoscopic procedure is based upon three factors: (1) a comprehensive appreciation of the effects of the procedure on the physiological responses of the patient; (2) an awareness of the potential complications; (3) a prudent, meticulous approach to all elements of anaesthetic management. Each of these areas will be discussed.

\section{Physiological Considerations}

Laparoscopy introduces three major physiological alterations in the anaesthetized patient. These trespasses against physiological homeostasis are the Trendelenburg position, an artificial pneumoperitoneum and the introduction of exogenous carbon dioxide.

\section{(A) Trendelenburg Position}

The Trendelenburg position was first described by Meyer, ${ }^{3}$ a student of Trendelenburg, and consisted of a 30-degree head-down tilt. It was originally advocated for pelvic surgery to facilitate exposure and to reduce blood loss. During World War I it became popular in the treatment of shocked patients as the position was empirically assumed to improve cerebral blood flow. In the management of shock the Trendelenburg position has been superseded by elevation of the legs only. This posture augments venous return from the lower extremities without introducing the potentially deleterious effects of the head-down tilt.

\section{(1) Cardiovascular Effects ${ }^{4}$}

The Trendelenburg position is uncomfortable. The conscious subject experiences a vascular engorgement of the head and neck due to increased venous pressure. 
Carotid pressure increases initially, but this gravitational effect may be moderated by the carotid baroreceptors. Guntheroth et al. ${ }^{5}$ have shown that carotid flow decreases when experimental animals are tipped head-down.

We have not found experimental data on the influence of the Trendelenburg position on cerebral or renal perfusion, but it is probable that both are adversely influenced. Renal perfusion may be decreased by gravitational influences. Any postural advantage to arterial flow to the brain would be negated by increased intracranial pressure secondary to venous engorgement within the rigid confines of the cranial vault.

\section{(2) Respiratory Effects}

The Trendelenburg position causes a decrease in vital capacity because of the weight of the abdominal viscera on the diaphragm. ${ }^{6}$ Scott and Slawson ${ }^{7}$ have shown that anaesthetized patients may be able to maintain adequate ventilation in this posture, but this is only possible if the patient can increase inspiratory efforts to overcome the abnormal ascent of the diaphragm.

Ventilation/perfusion relationships are affected by this abnormal posture.

(3) Hazards of Trendelenburg Tilt

(i) Brachial Plexus Palsy: Incorrectly applied shoulder braces cause compression or stretching of the nerve trunks of the brachial plexus. ${ }^{8}$

(ii) Regurgitation of Gastric Contents: The head-down tilt may cause passive regurgitation of gastric contents. Endotracheal intubation and careful suctioning prior to extubation prevent aspiration.

(iii) Inadvertent Endobronchial Intubation: Heinonen et al. ${ }^{9}$ have shown that there is an upward displacement of the hilum of the lung when an intubated patient is tipped head-down. Since the tracheal tube is fixed in position, the result may be an inadvertent bronchial intubation unless a suitably short tube is selected.

\section{(B) Artificial Pneumoperitoneum}

The introduction of several liters of gas into the peritoneal cavity increases intra-abdominal pressure and, when combined with Trendelenburg position may disturb cardiovascular and respiratory dynamics.

(1) Cardiovascular Effects: The cardiovascular effects of an artificial pneumoperitoneum without Trendelenburg position were examined by Smith et al. ${ }^{10}$ As insufflation proceeded, they observed progressive increases of intra-abdominal pressure with corresponding increases in femoral vein and central venous pressures. There was no evidence of obstruction of the inferior vena cava when intra-abdominal pressures were less than $25 \mathrm{~cm}$ of water, but they suggest that might occur with higher intra-abdominal pressures. Obstruction of venous blood flow might precipitate a situation comparable to the "supine hypotensive syndrome" of late pregnancy.

(2) Respiratory Effects: Pneumoperitoneum and head-down tilt cause an elevation of the diaphragm. ${ }^{11}$ Diaphragmatic elevation causes a decrease in expiratory 
reserve and residual lung volumes. Tidal volume may also decrease. ${ }^{11}$ Unless the patient can increase and maintain greater ventilatory efforts, these changes lead to hypercapnia and hypoxaemia.

Similar changes are observed if a pressure-limited respirator is used for controlled ventilation. Ventilation should be monitored with a respirometer and inspiratory pressure increased when the patient is positioned head-down. A volume-limited respirator is preferable for routine use.

Complications of Pneumoperitoneum: While pneumothorax or pneumomediastinum can be caused by the escape of gas through anomalies or from tears of the diaphragm, the common complications of an artificial pneumoperitoneum are due to incorrect positioning of the Verres needle or trocar.

We have had two serious complications at our hospital, caused by puncture of a mesenteric vessel and laceration of an internal iliac vein. Both patients bled profusely and developed sudden and profound hypotension. Emergency laparotomies were required to control blood loss.

Intestinal perforation occurred once and was detected by aspiration of intestinal fluid prior to insufflation.

Other potential complications include gas embolism from perforation of a blood vessel, injection of gas into an abdominal viscus and traumatic lysis of adhesions.

Parietal or subcutaneous emphysema can be caused by failure of the Verres needle to penetrate the peritoneum. Most of the insufflated gas can be released through the Verres Needle.

\section{(C) Exogenous Carbon Dioxide}

Carbon dioxide is used to create the pneumoperitoneum because it is nonexplosive and non-combustible. Carbon dioxide is much more soluble in blood than is nitrogen and would have only transient effects if intravascular embolization should occur.

When laparoscopy first became popular, significant cardiac dysrhythmias were noted. It was postulated that rapid vascular absorption of carbon dioxide might cause hypercapnia and precipitate disorders of cardiac rhythm.

Several investigators have demonstrated that normal arterial carbon dioxide tensions can be maintained during laparoscopy providing ventilation remains adequate. ${ }^{11-16}$

These investigators suggested that the cardiac dysrhythmias were related primarily to alveolar hypoventilation in the spontaneously-breathing or inadequately ventilated patient. Transperitoneal absorption of carbon dioxide exerted only a minor effect. Desmond and Gordon ${ }^{11}$ compared spontaneous with controlled ventilation and further subdivided those patients on controlled ventilation into two groups, those whose ventilation was determined by the Radford nomogram ${ }^{17}$ and those who were hyperventilated. They concluded that hyperventilation provided the best anaesthetic management.

Since these authors had not suggested an appropriate degree of hyperventilation, 24 patients undergoing laparoscopy at one hospital were ventilated with a minute volume determined by the Adelaide Ventilation Guide. 
TABLE II

Contraindications to Pelvic Laparoscopy

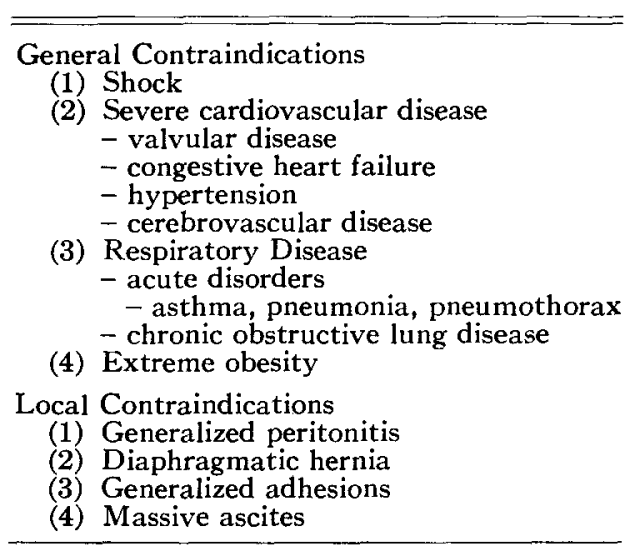

The Adelaide Ventilation Guide ${ }^{*}$ was developed by Sheila Kenny ${ }^{18}$ and is designed to predict an adequate minute volume for intubated, anaesthetized patients. In contrast to the complexities of the Radford nomogram, the Adelaide Ventilation Guide relates only two factors, minute volume in liters and body weight in pounds. When Kenny ${ }^{18}$ compared the Adelaide Ventilation Guide with the Radford Nomogram, she observed that the Ventilation Guide consistently indicated a minute volume two liters greater for adult patients than that suggested by the Radford Nomogram.

We felt that the Adelaide Ventilation Guide might be appropriate for laparoscopy because of its greater predicted minute volume. When we assessed 24 patients with controlled constant-volume ventilation, we observed only minor increases in arterial carbon dioxide concentrations. The mean increase in $\mathrm{PaCO}_{2}$ was 4 Torr. The increase in end-tidal carbon dioxide concentrations as assessed by a Model LBI Beckman Medical Gas Analyzert ranged from zero change to +1.2 per cent with a mean increase of +0.6 per cent. No cardiac dysrhythmias were observed during anaesthesia in this group of patients.

\section{Contraindications to Laparoscopy}

A classification of conditions in which laparoscopy is contra-indicated is summarized in Table II.

\section{Selection of Insufflating Equipment}

The anaesthetist is not only responsible for the complete care of the patient, but should also supervise the insufflation. The surgeon is frequently preoccupied with his laparoscopic observations and may not be alert to dangerous elevations in intra-abdominal pressure.

- Adelaide Ventilation Guide, Anaesthetic Laboratory, Adelaide Hospital, Dublin 8, Eire.

$\uparrow$ Beckman Instruments Incorporated, Electronic Instruments Division, 3900 River Road, Schiller Park, Illinois 60176, U.S.A. 
When laparoscopy was introduced at our hospital, a gynaecologist fabricated a system in which a carbon dioxide tank was connected to a reducing valve and a flowmeter. The system lacked a pressure relief valve.

We modified a surplus Heidbrink Kinetometer to provide a safer system. The bobbin flowmeter calibrated for carbon dioxide provided an accurate measurement of gas flow. A pressure relief valve was incorporated by Commander Thompson of our Hyperbaric Unit. Pressures in excess of 40 centimeters of water is vented to atmosphere. The instrument is serviceable and safe.

Since we are performing laparoscopy frequently, the hospital has also purchased a Stemm Insufflator which incorporates a pressure sensitive valve to interrupt gas flow when line pressures are excessive.

\section{Anaesthetic Technique}

The anaesthetic technique should compensate for the physiological disturbances discussed previously.

\section{Premedication}

Premedication is employed to reduce apprehension and is based upon the anaesthetist's preference.

\section{Anaesthetic Preparation}

(1) Intravenous cannula: Since the patient's hands are positioned by her side and are inaccessible during the procedure, we secure a plastic cannula in a hand or forearm vein and attach an extension to the tubing so that the injection site is situated conveniently.

(2) Induction: Induction is performed with thiopentone and succinylcholine in sequence. A short cuffed tulse is selected for intubation. The tip is passed about $5 \mathrm{~cm}$ beyond the larynx and is secured appropriately.

(3) Anaesthetic Agents: Anaesthetists at our hospital often employ nitrous oxide/ oxygen anaesthesia, supplemented with alphaprodine (Nisentil ${ }^{\circledR}$ ), a shortacting narcotic analgesic. Gallamine or curare are the relaxants most commonly employed for intraoperative muscle relaxation.

(4) Ventilation: Ventilation is controlled by a volume limited or pressure limited respirator. Respirometers are used to monitor tidal and minute volumes and to aid in adjusting ventilation. The Adelaide Ventilation Guide is favoured by several anaesthetists as a simple method of predicting adequate ventilation.

\section{Positioning of the Patient}

After the induction of anaesthesia, the patient is placed in the lithotomy position by securing the legs on Lloyd-Davis stirrups and dropping the foot of the table. The hands are positioned by the patient's side. We tape the hands to the lateral surface of the thighs since there is a possibility that the fingers might drop over the end of the table and be crushed when the foot of the table is elevated at the end of the procedure.

\footnotetext{
*Down Bros. and Mayer \& Phelps Ltd,, Toronto, Canada.
} 
Padded shoulder braces are positioned over the acromial processes. From experience with volunteers we have found these to be much more comfortable if a small pillow is placed between the braces and the patient.

After the insufflation has been completed, the table is positioned with about 18 to 20 degrees head-down tilt. The table is brought back to the neutral position before the gas is vented at the end of the procedure.

\section{Monitoring Equipment}

Cardio-respiratory monitoring equipment should include a cardioscope and respirometer as well as the routine sphygomomanometer cuff. Adequate illumination is important. When the room is darkened to improve the surgeon's visualization, we use the $X$-ray view boxes to provide alternate illumination.

The end-tidal carbon dioxide analyzer is a useful and sensitive monitor which provides a breath-by-breath assessment of alveolar carbon dioxide concentration.

\section{SUMMaRY}

The anaesthetic management of laparoscopy is based upon an appreciation of the physiological alterations demanded by laparoscopy. Over three hundred laparoscopies have been performed at the Vancouver General Hospital without a single significant complication of anaesthesia.

\section{RÉSUMÉ}

Depuis qu'il est possible de se procurer un appareillage chirurgical amélioré, la laparoscopie pelvienne est devenue une technique chirurgicale qui gagne de la popularité. Pour que la conduite de l'anesthésie demeure un succès, il faut faire une évaluation des changements physiologiques produits par la position de Trendelenbourg, un pneumopéritoine artificiel et l'administration de gaz carbonique exogène. Parmi les contrindications de la laparoscopie, citons : le choc, une maladie cardiorespiratoire, une obésité extrême, une péritonite généralisée, des adhérences de l'ascite et une hernie diaphragmatique. Nous recommandons de la prudence dans la conduite de l'anesthésie et l'usage de moniteurs.

\section{REFERENCES}

1. Steptoe, P.C. Laparoscopy in Gynaecology. E. \& S. Livingston, London, 1967.

2. Cohen, M.R. Laparoscopy, Culdoscopy \& Gynaecology. W.B. Saunders Co., Philadelphia, 1970.

3. WeIl, M.H., Udjohr, V.N., \& Allen, K.S. The head-down position in treatment of shock. Surgery, Gynecology \& Obstetrics 116: 669 (1963).

4. Wilkins, R.W., Bradley, S.E., \& Friedland, C.K. The acute circulatory effects of the head-down position (Negative $G$ ) in normal man with a note on some measures designed to relieve cranial congestion in this position. J. Clin. Invest. 29: 940 (1950).

5. Guntheroth, W.G., Abel, F.L., \& Mullins, G.L. The effect of Trendelenburg's position on blood pressure and carotid flow. Surg. Gynec. \& Obstet. 119: 345 (1964).

6. Case, E.H. \& Stiles, J.A. The effect of various surgical positions on vital capacity. Anaesthesiology 7: 29 (1946). 
7. Scott, D.B. \& Slawson, K.B. Respiratory effects of prolonged trendelenburg position. Brit. J. Anaesth. 40: 103 (1968).

8. Britt, B.A. \& Gondon, R.A. Peripheral nerve injuries associated with anaesthesia. Canad. Anaesth. Soc. J. 11: 514 (1964).

9. Heinonen, J., Takki, S., \& Tammisto, T. Effect of the Trendelenburg tilt and other procedures on the position of endotracheal tubes. Lancet $i$ : 850 (1969).

10. Smith, I., Benzie, R.J., Gornon, N.L.M., Kelman, G.R., \& Swapp, G.H. Cardiovascular effects of peritoneal insufflation of carbon dioxide for laparoscopy. Brit. Med. J. 3: 410 (1971).

11. Desmond, J. \& Gondon, R.A. Ventilation in patients anaesthetized for laparoscopy. Canad. Anaes. Soc. J. 17: 378 (1970).

12. Baratz, R.A. \& Karis, J.H. Blood gas studies during laparoscopy under general anaesthesia. Anesthesiology 30: 463 (1969).

13. Axexander, G.D., NoE, F.E., \& Brown, E.M. Anesthesia for pelvic laparoscopy. Anesth. \& Analg, 48: 14 (1969).

14. Berenyi, K.J., Fujita, T., \& Siegler, A.M. Carbon dioxide laparoscopy. Acta Anaesthesia Scandinav. 14:77 (1970).

15. Seed, R.F., Shakespeare, T.F., \& Muldoon, M.J. Carbon dioxide homeostasis during anesthesia for laparoscopy. Anaesthesia 25: 223 (1970).

16. Hodgson, C., McClella and, R.M.A., \& Newton, J.R. Snme effects of the peritoneal insufflation of carbon dioxide at laparoscopy. Anaesthesia 25: 382 (1970).

17. RadFond, E.P. Ventilation standards for use in artificial respiration. J. Appl, Physiol. 7: 451 ( 1955).

18. KenNy, S. The Adelaide Ventilation Guide. Brit. J. Anaesth. 39: 31 (1967). 